\title{
Perancangan Jendela dan Partisi Pembatas dengan Pertimbangan Kenyamanan Termal
}

\author{
Daffa Aditya Pratama1, Irwana Zulfia Budiono² \\ 1, Mahasiswa Desain Interior Telkom University, ${ }^{2}$ Dosen Fakultas Industri Kreatif Telkom University \\ 1, daffa.daffa48@gmail.com, ${ }^{2}$ irwanazulfiab@telkomuniversity.ac.id
}

\begin{abstract}
ABSTRAK
Pemanasan global menjadi isu yang semakin sering diperbincangkan selama beberapa tahun terakhir. Pemanasan global telah mempengaruhi semua negara termasuk Indonesia. Akibat yang ditimbulkan dari pemanasan global adalah naiknya temperatur rata-rata yang pada akhirnya berdampak pada kenyamanan termal. Kenyamanan termal dibutuhkan dalam semua ruang yang dihuni manusia termasuk bangunan masjid. Dalam kasus masjid SMA Muslimin Rongga, kenyamanan termal tidak berjalan dengan baik karena kurangnya perhatian pada perancangan jendela. Fasilitas yang ada juga tidak mendukung untuk proses belajar-mengajar yang berlangsung dalam masjid bagi siswa SMA Muslimin Rongga. Fasilitas utama yang tidak ditemukan dalam masjid adalah partisi pembatas antara laki-laki dan perempuan. Tantangan yang dihadapi adalah untuk membuat furnitur yang dapat meningkatkan kelancaran aktivitas dalam masjid tanpa mengganggu kenyamanan termal terlalu banyak. Kondisi kenyamanan termal yang kurang baik tidak akan berjalan dengan baik jika furnitur yang ada dalam masjid juga terlalu banyak. Dalam perancangan ini perancang membuat desain jendela dengan mempertimbangkan kenyamanan termal dan sebuah partisi pembatas antara laki-laki dan perempuan yang dapat diubah menjadi meja dan kompartemen penyimpananan barang, buku, dan/atau mukena kaum perempuan. Partisi bekerja dengan sistem bongkar pasang dilengkapi dengan anyaman bambu yang berperan sebagai akses udara agar tidak terkumpul di satu sisi ruang. Metode penelitian yang digunakan adalah metode penelitian kualitatif dengan pendekatan deskriptif yang dibantu dengan studi literatur terkait pemanasan global, kenyamanan termal manusia serta studi ergonomi dan antropometri. Penulis dan tim abdi masyarakat melakukan kunjungan lokasi untuk menganalisa ruangan dan mengumpulkan data-data yang dibutuhkan seperti temperatur rata-rata, tingkat kelembaban, dan arah angin. Dengan hasil analisa dan studi yang telah dilakukan diharapkan perancangan ini dapat meningkatkan tingkat kenyamanan termal masjid serta dapat memenuhi kekurangan fasilitas masjid yang sesuai dengan standar dan kebutuhan manusia tanpa mengganggu tingkat kenyamanan termal masjid.
\end{abstract}

Kata kunci: jendela; partisi pembatas; meja belajar; furnitur multifungsi; kenyamanan termal

\begin{abstract}
Global warming became one of the most spoken issue for the last few years. Global warming has affected all nations including Indonesia. One of the phenomena caused by global warming is the increasing of annual mean temperature, which eventually affected human thermal comfort. Thermal comfort is a necessity in a room which human being is its inhabitant, including a building such as mosque. In the case of Masjid SMA Muslimin Rongga, thermal comfort is barely achieved due to its lack of planning in window and ventilation design. The existing facility is also quite unsupportive to accommodate learning activity for students inside the mosque properly. One of the main facilities that is missing is physical separator between men and women. The main challenge to this study is to build a furniture that can to not only accommodate various activity but also do not worsen the thermal comfort inside the building. Thermal comfort would hardly be achieved if there are too many furniture inside the building. In this study, designer has made a window design with thermal comfort consideration and a separator partition that can be transformed to a desk and a compartment for students' belongings. The partition works with knock-down system and provided with a woven bamboo as an access for wind to circulate around the building. The research method used in this study is qualitative method with descriptive approach supported by literature study regarding global warming, thermal comfort, and ergonomic study. Writer and abdi masyarakat team went to SMA Muslimin Rongga to analyse the
\end{abstract}


building and to gather data such as mean temperature, humidity level, and wind direction. With all the study and analysis, the increment in thermal comfort is to be expected whilst the completeness of the required primary facility is nevertheless considered.

Keywords: window; separator partition; desk; multifunctional furniture; thermal comfort

\section{PENDAHULUAN}

Pemanasan global adalah istilah moderen yang digunakan untuk mendeskripsikan bahwa iklim global menjadi semakin hangat bukan hanya karena sebab alami, namun juga karena sebab antropogenik (dipengaruhi manusia) (Philander, 2012, p. 640). Sebanyak kurang-lebih 97\% saintis setuju bahwa manusia bertanggungjawab atas perubahan drastis iklim Bumi sejak dua abad lalu (Shahzad, 2015, p. 1). Menurut Philander (2012, p. 640-644), terdapat beberapa sebab alami yang mempengaruhi terjadinya pemanasan global, antara lain: a) iklim dan cuaca, b) efek rumah kaca, c) orbit Bumi terhadap matahari, kemiringan poros Bumi, dan e)pergeseran lempeng tektonik. Indonesia selama beberapa tahun terakhir telah terdampak pemanasan global ditimbang dari meningkatnya temperatur rata-rata tahunan. Kenaikan temperatur tahunan mungkin tidak akan dirasakan secara langsung, namun perlahan-lahan jika tidak segera diatasi, lingkungan akan menjadi semakin tidak layak huni. Manusia sangatlah sensitif terhadap suhu di sekitar. Jika sedikit ketidaknyamanan tidak segera dicari solusinya, permasalahan yang kecil akan menjadi besar. Pemanasan global menjadikan kenyamanan termal yang optimal hal yang sangat penting. Kenyamanan termal adalah kondisi dimana seseorang merasakan dorongan seminimal mungkin atau tidak sama sekali untuk keluar dari situasi tidak nyaman; dengan tetap mempertimbangkan fakta bahwa manusia tidaklah pasif dan seringkali mencari stimulasi sebagai hiburan (Parsons, 2014, p. 257). Kenyamanan termal dalam ruang dimana manusia menghabiskan sebagian besar waktunya adalah salah satu pertimbangan yang penting untuk mendapatkan hasil desain yang baik. Menurut Ken Parsons (2019, p. 1), terdapat tujuh faktor dasar yang mempengaruhi kenyamanan termal manusia, antara lain : a) temperatur udara, b) suhu radiasi, c) kelembaban, d) arah angin, e) panas hasil metabolisme manusia, f) pakaian yang dipakai manusia, g) kemampuan beradaptasi terhadap lingkungan. Manusia dengan sadar atau tidak akan selalu berusaha menyesuaikan diri dengan lingkungan sekitar. (Parsons, 2014, p. 59). Menjaga kenyamanan termal untuk tetap optimal adalah hal yang penting karena tingkat kenyamanan seseorang akan berpengaruh pada tingkat konsentrasi dan stres pengguna ruang. Stres muncul sebagai respon tubuh karena adanya ancaman, baik ancaman nyata atau ancaman yang datang hanya dalam pikiran seseorang (Elsamahy \& Abd El-Fattah, 2018, p. 122). Paparan kondisi termal yang tidak optimal dalam waktu yang lama dapat mempengaruhi perilaku dan kondisi psikologis seseorang (Parsons, 2014, p. 74). Tingkat stres yang berlebihan dapat berakibat fatal pada kesehatan seperti penyakit jantung, tekanan darah, mual, dan sakit kepala (Elsamahy \& Abd El-Fattah, 2018, p. 121). Penggunaan pakaian yang berlapis, seperti busana ibadah umat muslim juga berpengaruh pada kenyamanan termal manusia. Setiap satu lapis pakaian menambah beban kerja sistem metabolisme tubuh manusia sebesar 4\% (Parsons, 2014, p. 211). Ruang yang terlalu panas akan menyebabkan ketidaknyamanan yang sama dengan ruang yang terlalu dingin. Efek yang sama berpengaruh dalam semua ruang yang dihuni oleh manusia termasuk bangunan masjid. Bangunan masjid adalah sebuah tempat untuk umat Islam melakukan peribadatan, perkumpulan, menyebarkan pendidikan islam, dan fungsi sosial lainnya. Bangunan masjid termasuk sebagai ruang publik karena semua orang, semua kalangan dapat masuk dengan bebas (Dyer \& Ngui, 2010, p. 10).

Kegiatan seperti beribadah di dalam masjid membutuhkan tingkat kenyamanan termal yang optimal. Ruangan yang nyaman akan membantu pengguna tetap berkonsentrasi penuh terhadap aktivitas ibadah yang dilakukan. Ibadah dalam masjid pada umumnya memerlukan waktu yang relatif tidak sebentar sehingga tingkat stres pengguna ruang harus dipertimbangkan. 


\section{D"AFin}

Vol. 6, No. 2, Desember 2021, pISSN 2527-2853, eISSN 2549-2985

Selain kenyamanan termal, fasilitas masjid juga termasuk hal yang tidak dapat dikesampingkan. Fasilitas seperti mimbar dan pembatas antara kaum perempuan dan laki-laki sangat dianjurkan atau bahkan harus ada dalam sebuah bangunan masjid demi kelancaran penerapan syariat Islam. Pembatas antara laki-laki dan perempuan khususnya diperlukan demi menjaga nilai islam dan kekhusyukan beribadah. Dalam kaitannya dengan kenyamanan termal, pembatas ruang tentu akan berpengaruh terhadap sirkulasi udara dalam ruang. Terdapat beberapa aspek dari sebuah pembatas untuk mendukung berjalannya sirkulasi udara yang baik seperti tinggi pembatas, material yang digunakan, serta ada atau tidaknya bukaan/akses udara pada pembatas yang digunakan. Material seperti kain akan lebih menoleransi pergerakan udara dibanding material solid seperti kayu.

Masjid SMA Muslimin Rongga sebagai kasus studi memiliki kondisi kenyamanan termal yang buruk. Buruknya kenyamanan termal dalam masjid disebabkan oleh perancangan masjid yang kurang pertimbangan. Jendela yang ada tidak mendukung kelancaran sirkulasi udara dalam ruang. Dari 32 buah jendela yang ada, hanya 16 yang dapat dibuka sedangkan sisanya adalah jendela permanen. Akses untuk keluar udara panas juga sama buruknya. Jendela transom yang terletak diatas jendela utama berupa jendela permanen tanpa bukaan untuk udara panas keluar ruangan. Udara panas yang terkumpul dalam ruang kemudian mengurangi efektivitas udara segar untuk masuk ke ruangan sehingga kondisi udara dalam ruang tidak bergerak. Masjid SMA Muslimin Rongga juga belum memiliki partisi pembatas antara pria dan wanita. Sedangkan keberadaan furnitur dalam ruang pasti akan berpengaruh pada kenyamanan termal ruang. Furnitur yang memiliki bentuk fisik akan menghalangi pergerakkan udara dan menyebabkan udara berhenti atau berganti arah yang pada akhirnya memengaruhi kenyamanan termal secara general. Meskipun demikian, keberadaan partisi tetap menjadi sebuah kebutuhan primer untuk bangunan masjid. Selain tidak memiliki pembatas pria dan wanita, masjid SMA Muslimin Rongga juga memiliki fasilitas yang sangat minim ditimbang dari kebutuhan ruang untuk mendukung selain proses ibadah juga proses belajar-mengajar keagamaan. Masjid tidak memiliki fasilitas penting seperti meja, rak mukena, serta rak Al-Qur'an. Kekurangankekurangan yang dimiliki masjid SMA Muslimin Rongga mendasari tujuan penulis untuk membuat sebuah furnitur yang mampu mengakomodasi banyak fungsi dengan mempertimbangkan kenyamanan termal dalam masjid yang memiliki luas area interior yang kecil. Penulis mendesain sebuah partisi pembatas yang dapat berperan sebagai pembatas, meja kecil, sekaligus sebagai kompartmen untuk menyimpan barang seperti buku, mukena, dan/atau Al-Qur'an. Partisi terbuat dari material kayu yang dilengkapi dengan celah-celah untuk akses sirkulasi udara. Partisi bekerja dengan sistem bongkar-pasang untuk berubah fungsi dari partisi menjadi meja kecil. Dengan partisi pembatas pria dan wanita yang multifungsi, kenyamanan termal dapat dikendalikan dengan lebih mudah. Ketika sedang tidak digunakan, partisi dapat digunakan untuk fungsi lain daripada hanya memenuhi ruang yang dapat berakibat pada naiknya suhu ruang.

\section{METODE PENELITIAN}

Metode penelitian adalah sebuah sarana bagi peneliti untuk mempelajari permasalahan yang ada. Menurut Creswell (2009) terdapat tiga pendekatan metode penelitian antara lain: a) pendekatan kuantitatif (terstruktur), b) pendekatan kualitatif (tak terstruktur), dan c) pendekatan campuran. Penulis menggunakan pendekatan kualitatif dalam penelitian ini. Pendekatan kualitatif didukung dengan menggunakan analisa deskriptif yang didapatkan melalui sumber literatur maupun jurnal mengenai kenyamanan termal pada ruang publik.

Studi literatur terkait pemanasan global di Indonesia dan khususnya di Bandung digunakan untuk memahami tren memburuknya tingkat kenyamanan manusia dalam bangunan terkait 
dengan kondisi panas yang sulit ditolerir. Sedangkan studi literatur terkait kenyamanan termal berperan untuk mendapatkan gambaran jelas tentang situasi dan kondisi seperti apa yang dibutuhkan manusia untuk mendapatkan kenyamanan yang optimal. Studi ergonomi dan antropometri digunakan sebagai landasan perancangan untuk menghasilkan solusi desain yang paling sesuai dengan kebutuhan dan standar manusia.

\section{HASIL PENELITIAN DAN PEMBAHASAN}

\section{A. Permasalahan yang Ditemukan pada Masjid SMA Muslimin Rongga}

Masjid SMA Muslimin Rongga pada sebagian besar waktunya digunakan sebagai sarana beribadah siswa-siswi SMA Muslimin Rongga dan sebagian waktu lainnya digunakan sebagai sarana pendidikan agama islam. Terdapat fungsi tambahan lainnya yaitu sebagai balai pertemuan siswa dan masyarakat sekitar pada akhir pekan. Sirkulasi udara yang baik menjadi sebuah keharusan terlebih lagi dalam ruang yang digunakan untuk aktivitas yang padat seperti masjid SMA Muslimin Rongga. Namun hal itu tidak terjadi dalam masjid SMA Muslimin Rongga. Berdasarkan kunjungan lokasi yang telah dilaksanakan tim abdi masyarakat, kondisi interior masjid terasa sejuk dikarenakan kondisi tipografi serta penggunaan material dengan penyimpanan panas untuk pembentuk fasad bangunan. Namun walaupun suhu ruangan berada pada lingkup 24 celcius, sirkulasi udara dalam ruang tidak bergerak dan dikhawatirkan dapat mengakibatkan ketidaksesuaian pada kenyamanan termal saat jumlah pengguna dalam kapasitas tinggi. Setelah diteliti, kondisi kenyamanan termal yang buruk diakibatkan oleh perancangan sistem jendela yang buruk.

Jendela yang ada berjumlah delapan buah modul dengan empat buah jendela di setiap modul. Pada setiap modul terdapat dua jendela yang dapat dibuka dan dua jendela permanen. Secara keseluruhan terdapat 16 buah jendela yang dapat dibuka dan 16 buah jendela permanen. Selain jendela, terdapat juga jendela transom yang terletak diatas jendela utama. Setiap modul jendela memiliki empat buah jendela transom yang semuanya merupakan jendela permanen tanpa bukaan/akses untuk keluar masuk udara.

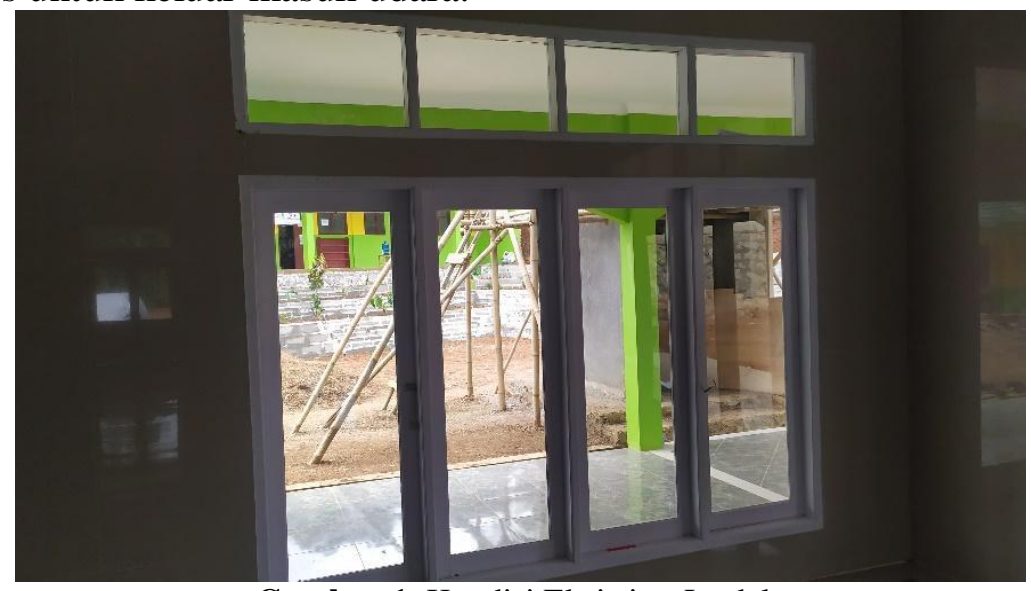

Gambar 1. Kondisi Eksisting Jendela

Sumber: Dokumentasi Pribadi (2021)

Material yang digunakan pada jendela transom merupakan salah satu permasalahan utama. Udara panas yang terakumulasi dalam ruang tidak memiliki akses keluar sehingga menumpuk pada area ceiling dan membuat kondisi keseluruhan masjid menjadi panas.

Kegiatan belajar mengajar yang diselenggarakan dalam area masjid juga tidak didukung dengan fasilitas yang memadai. Masjid tidak memiliki meja untuk mendukung kegiatan bacatulis dan hanya terdapat satu rak penyimpanan untuk memfasilitasi seluruh kebutuhan siswa dan guru. Rak untuk meletakkan mukena bagi siswi perempuan, peralatan tulis, serta Al-Qur'an 
juga tidak ditemukan dalam masjid. Salah satu permasalahan utama yang menjadi prioritas adalah tidak adanya pembatas antara laki-laki dan perempuan dalam masjid.

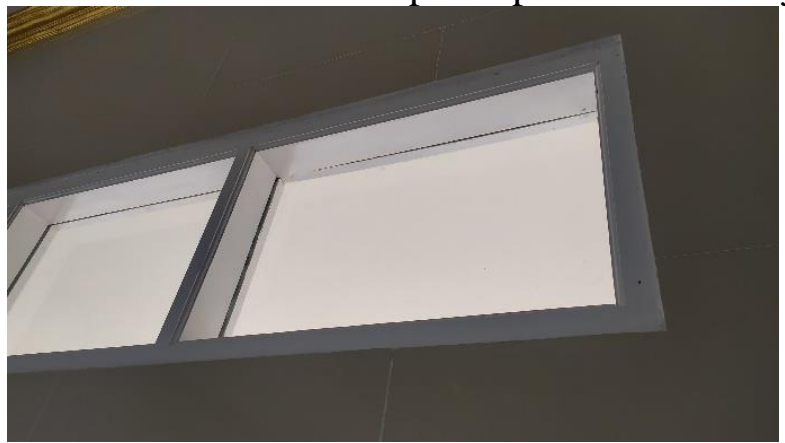

Gambar 2. Jendela Transom Tanpa Akses Untuk Udara Panas Keluar Sumber: Dokumentasi Pribadi (2021)

\section{B. Desain Jendela dan Kenyamanan Termal}

Udara yang tidak bergerak dalam masjid SMA Muslimin Rongga dikarenakan sistem ventilasi masjid yang buruk. Dalam hukum termodinamika, udara yang lebih panas akan berada di area ceiling dan udara yang lebih dingin akan berada di area lantai. Namun dalam masjid SMA Muslimin Rongga tidak terdapat akses udara panas yang berkumpul di area ceiling untuk keluar dari ruangan sehingga semakin menekan udara panas ke area lantai. Udara panas yang semakin berkumpul mendekati lantai menghalangi efektivitas udara dingin untuk masuk ke dalam bangunan sehingga berakibat pada kondisi udara yang tidak bergerak.

Dengan pertimbangan kelancaran pergerakan udara, penulis menggunakan roster sebagai pengganti jendela transom. Alasan pemilihan roster juga mempertimbangkan kondisi akustik yang buruk karena terlalu banyak penggunaan kaca dan keramik. Dengan mengurangi penggunaan material kaca dan keramik diharapkan kenyamanan akustik juga dapat ditingkatkan. Demi input udara yang lebih maksimal, perancang mengubah keempat jendela dalam satu modul untuk dapat dibuka-tutup. Berikut adalah desain jendela hasil perancangan:
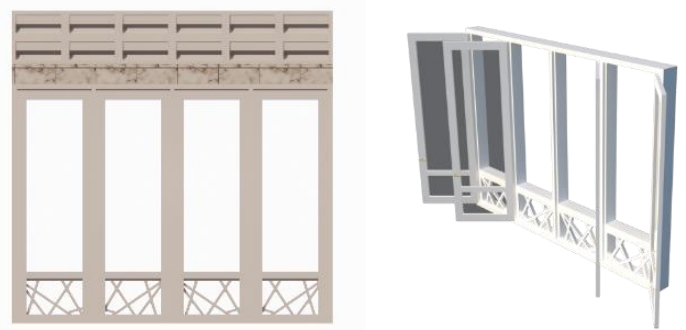

Gambar 3. Desain Jendela Sumber: Dokumentasi Pribadi (2021)

Dengan mengubah jendela dengan roster diharapkan cross ventilation dapat berjalan dengan baik sehingga pertukaran udara dingin dan panas dapat berjalan seimbang untuk meningkatkan kenyamanan termal dalam ruang. Berikut adalah simulasi perkiraan pergerakan udara yang diharapkan dari penggunaan roster: 


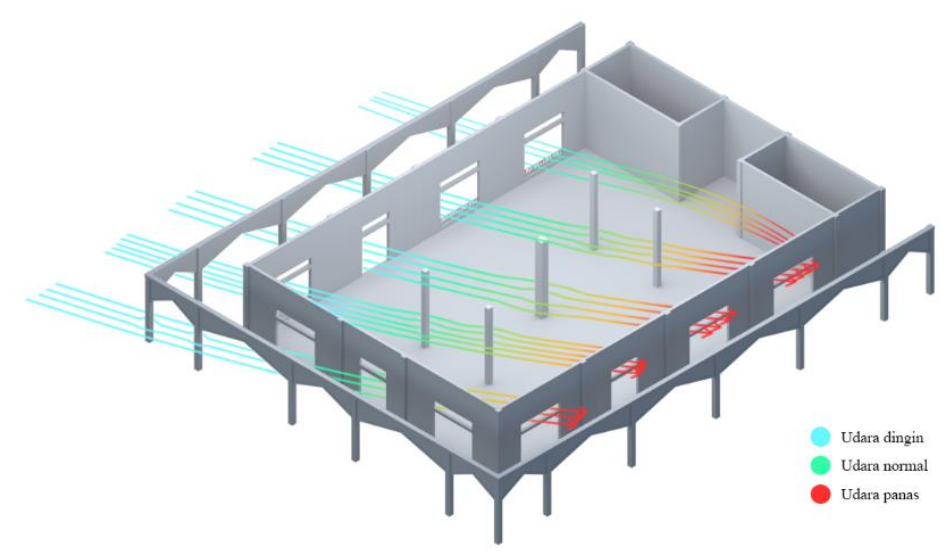

Gambar 4. Simulasi Pergerakan Udara Dalam Ruang Sumber: Dokumentasi Pribadi (2021)

Udara dingin masuk melalui bukaan yang telah dirancang untuk memaksimalkan jumlah udara yang masuk. Udara akan segera digantikan dengan udara yang lebih dingin dan menekan udara yang lebih panas ke atas. Udara panas kemudian keluar melalui roster.

\section{Desain Partisi Pembatas dan Kenyamanan Termal}

Terdapat beberapa kunci dalam pemikiran pengambilan solusi desain. Pertama, masjid SMA Muslimin Rongga digunakan bukan hanya untuk keperluan sholat berjama'ah namun juga sebagai tempat belajar-mengajar, sehingga partisi yang di desain harus fleksibel dalam arti dapat dipindah-tempatkan dengan mudah. Kedua, ketika partisi sedang digunakan, partisi menjadi kehilangan fungsinya dan hanya memenuhi tempat saja.

Konsep utama perancangan yang diterapkan adalah sebuah partisi modular dengan sistem bongkar-pasang yang memungkinkan partisi untuk berubah fungsi menjadi furnitur lain ketika sedang tidak digunakan. Berikut adalah gambaran umum hasil perancangan:

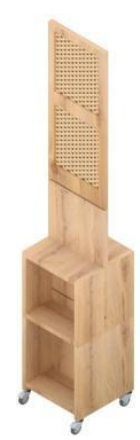

Gambar 5. Hasil Desain Partisi Pembatas

Sumber: Dokumentasi Pribadi (2021)

Pertimbangan lain yang dipakai adalah aspek kenyamanan termal masjid. Kondisi kenyamanan termal masjid yang buruk mengharuskan desain partisi untuk beradaptasi dan mendukung kelancaran sirkulasi udara. Pada modul bagian atas partisi terdapat pola anyaman bambu dengan celah-celah diantaranya sebagai sirkulasi udara. Udara juga dapat bergerak melalui area bawah partisi. 


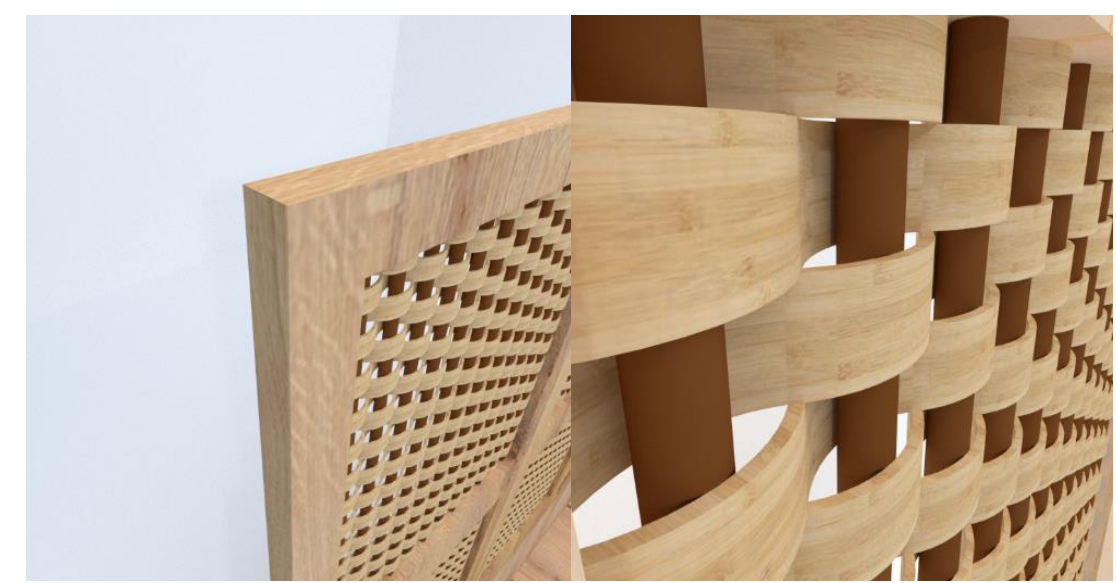

Gambar 6. Detail Anyaman Bambu Pada Partisi

Sumber: Dokumentasi Pribadi (2021)

Pola anyaman didesain sedemikian rupa sehingga penglihatan antara bagian laki-laki dan perempuan benar-benar dibatasi sehingga kedua pihak tidak bisa mengintip aktivitas satu sama lain. Konsentrasi pengguna juga harus dijaga sehingga gangguan sekecil apapun harus dihindari. Gambar dibawah menunjukkan bagaimana udara bergerak melalui celah-celah yang ada pada partisi pembatas:

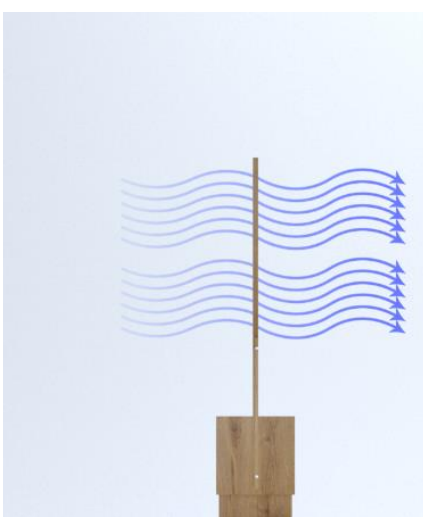

Gambar 7. Pergerakan Udara Melintasi Partisi Pembatas Sumber: Dokumentasi Pribadi(2021)

\section{Mekanisme Bongkar-Pasang}

Bentuk dasar partisi mengambil bentuk persegi dari partisi pada umumnya dan terdiri dari dua bagian utama yaitu bagian atas dan bagian bawah. Bagian bawah digunakan sebagai penyokong partisi utama sekaligus menjadi tempat penyimpanan barang dan bagian atas digunakan sebagai partisi utama yang dapat ditransformasikan menjadi sebuah meja. 


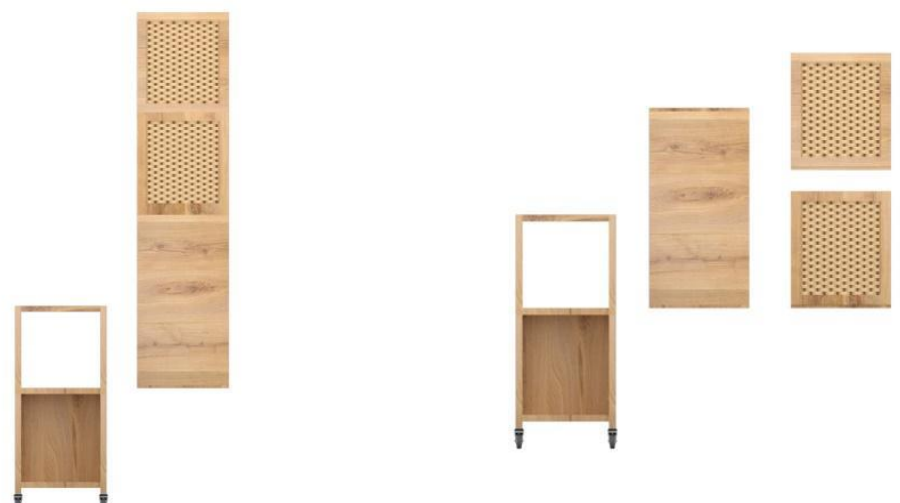

Gambar 8. Mekanisme Bongkar-Pasang 1
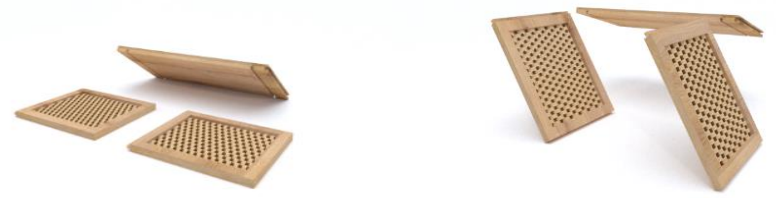

Gambar 9. Mekanisme Bongkar-Pasang 2
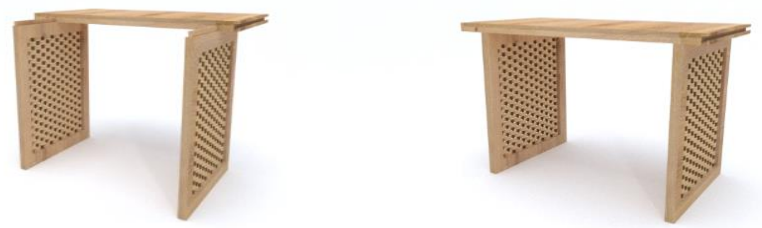

Gambar 10. Mekanisme Bongkar-Pasang 3

\section{KESIMPULAN}

Permasalahan utama yang dihadapi masjid SMA Muslimin Rongga adalah kondisi kenyamanan termalnya yang buruk. Desain jendela yang dibangun dengan kurang pertimbangan membuat udara panas terperangkap di dalam ruang tanpa akses untuk keluar. Tim abdi masyarakat merancang desain jendela dengan mengganti jendela bagian atas dengan penggunaan roster. Selain memberikan akses udara, penggunaan roster juga bertujuan untuk mengurangi penggunaan kaca demi meningkatkan kenyamanan akustik ruangan. Tim abdi masyarakat juga mengubah model jendela. Model jendela yang ada di lokasi berupa delapan modul jendela dengan empat jendela dalam tiap modulnya. Dari empat jendela yang ada dalam satu modul, hanya dua yang dapat dioperasikan, sedangkan dua jendela sisanya adalah jendela 
permanen. Dalam solusi desain yang ditawarkan, tim abdi masyarakat mengubah keempat jendela dalam satu modul untuk semuanya dapat dioperasikan. Kondisi yang buruk diperparah dengan kurangnya fasilitas yang mendukung aktivitas dalam masjid. Fasilitas utama yang tidak ditemukan dalam masjid SMA Muslimin Rongga adalah partisi pembatas antara laki-laki dan perempuan. Fasilitas pendukung lainnya seperti rak buku, rak mukena, dan meja juga kurang layak untuk mengakomodasi kegiatan belajar-mengajar siswa SMA Muslimin Rongga yang juga berlangsung dalam masjid. Perancangan desain partisi harus mempertimbangkan kondisi kenyamanan termal masjid. Selain kenyamanan termal, desain partisi juga harus mempertimbangkan fleksibilitas furnitur dalam arti dapat dipindah-tempatkan dengan mudah untuk mendukung proses belajar-mengajar. Berdasarkan faktor-faktor yang telah disebutkan, desain partisi yang telah disepakati dibuat modular dan dapat dibongkar-pasang menjadi sebuah meja dan kompartemen untuk menyimpang barang. Partisi tersusun dari dua bagian yaitu bagian atas dan bagian bawah. Bagian atas adalah bagian dari partisi yang dapat diubah menjadi meja, sedangkan bagian bawah adalah bagian dari partisi yang dapat dimanfaatkan sebagai kompartemen penyimpanan barang. Partisi dilengkapi dengan roda agar lebih mudah untuk memindahkan furnitur. Selain kenyamanan termal, kenyamanan akustik juga harus ditingkatkan. Kenyamanan akustik yang kurang baik dipengaruhi oleh banyaknya penggunaan material kaca dan keramik dalam ruangan dengan terlalu sedikit furnitur pengisi ruang.

\section{DAFTAR PUSTAKA}

Creswell, J.W. (2009). Research Design: Qualitative, Quantitative and Mixed Method Approaches. Edisi ketiga. Los Angeles: SAGE Publications.

Dyer, H. \& Ngui, M. (2010). Watch This Space - Designing, Defending, and Sharing Public Places. Toronto: Kids Can Press.

Elsamahy, E. \& Abd El-Fattah, R.M. (2018). Designing Non-Stressed Psychological Public Spaces. BAU Journal: Health \& Well-Being. Edisi Spesial: 1st International Conference on Urban Health \& Wellbeing UWHB2018, https://www.researchgate.net/publication/328718733

Parsons, K. (2014). Human Thermal Environments - The Effects of Hot, Moderate, and Cold Environment on Human Health, Comfort, and Performance. Edisi ketiga. Boca Ranton: CRC Press.

Parsons, K. (2019). Human Thermal Comfort. Boca Ranton: CRC Press.

Philander, S.G. (2012). Encyclopedia of Global Warming \& Climate Change. Edisi kedua. Thousand Oaks: SAGE Publications.

Shahzad, U. (2015). Global Warming Causes, Effects and Solutions. Durreesamin Journal. Vol. 1 No. 4, https://www.researchgate.net/publication/316691239 
Daffa Aditya Pratma ${ }^{1}$, Irwana Zulfia Budiono ${ }^{2}$

Perancangan Jendela dan Partisi Pembatas dengan Pertimbangan Kenyamanan Termal 